\title{
COVID-19 infection: Disease detection and mobile technology
}

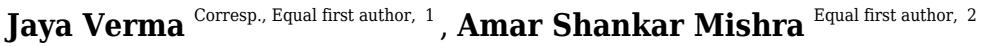 \\ ${ }^{1}$ Amity University, Noida, Uttar Pradesh, India \\ 2 \\ CIPL, New Delhi, Delhi, India \\ Corresponding Author: Jaya Verma \\ Email address: jayaverma745@gmail.com
}

Background: A pneumonia outbreak of unknown etiology took place in Wuhan, Hubei province, China $\&$ spread quickly worldwide in December 2019. Chinese Center for Disease Control and Prevention (CCDC) identified a novel beta-coronavirus called 2019-nCoV, now officially known as severe acute respiratory syndrome coronavirus 2 (SARS-CoV2) that is responsible for the pandemic. The coronavirus COVID-19 affected 215 countries and territories around the world and more than 99 hundred thousand people at present (Angela et al., 2020). At present, there are no specific vaccines or treatments are available for COVID-19. However, there are many ongoing clinical trials are evaluating potential treatments. At this time the experts recommend precautions such as social distancing, hand washing, and wearing face masks to reduce disease transmission. This review article aims to improve the readers' awareness towards the important role of mobile technology for SARS-CoV-2.

Methodology: To achieve this objective, we performed a COVID-19 literature review from various sources that include data from the published articles as well as World Health Organization reports on coronavirus disease and how mobile technology is useful to fight against this disease.

Results: Mobile technology can be helpful in mapping disease spread and provides an easy way to provide awareness that promotes safety and adoption of necessary precautions to mitigate and stop community transmission.

Conclusion: The spread rate of COVID-19 is very high and until now no vaccines are available to control this disease. To this end we should leverage other avenues such as digital technologies to protect ourselves from this disease. Mobile technology such as smartphones are playing an important role in this pandemic, by launching apps to track coronavirus infected people. These apps are very easy to use and provide self-isolation guidelines as well as other safety tips. 


\section{COVID-19 infection: Disease detection and mobile technology}

2 Jaya Verma Corresp, Equal first author, 1 and Amar Shankar Mishra Equal first author, 2

$3 \quad{ }^{1}$ Amity University, Noida, India

$4 \quad{ }^{2}$ CIPL, New Delhi

5 Corresponding author:

6 Jaya Verma ${ }^{1}$

7 Sector-125, Noida, Uttar Pradesh-201313, India

8 Email address: jayaverma745@gmail.com

\section{Abstract}

Background: A pneumonia outbreak of unknown etiology took place in Wuhan, Hubei province,

11 China \& spread quickly worldwide in December 2019. Chinese Center for Disease Control and

12 Prevention (CCDC) identified a novel beta-coronavirus called 2019-nCoV, now officially known

13 as severe acute respiratory syndrome coronavirus 2 (SARS-CoV2) that is responsible for the pandemic. The coronavirus COVID-19 affected 215 countries and territories around the world and more than 99 hundred thousand people at present (Angela et al., 2020). At present, there are no specific vaccines or treatments are available for COVID-19. However, there are many ongoing

17 clinical trials are evaluating potential treatments. At this time the experts recommend precautions such as social distancing, hand washing, and wearing face masks to reduce disease transmission. This review article aims to improve the readers' awareness towards the important role of mobile technology for SARS-CoV-2. 
21 Methodology: To achieve this objective, we performed a COVID-19 literature review from

22 various sources that include data from the published articles as well as World Health Organization

23 reports on coronavirus disease and how mobile technology is useful to fight against this disease.

24 Results: Mobile technology can be helpful in mapping disease spread and provides an easy way

25 to provide awareness that promotes safety and adoption of necessary precautions to mitigate and

26 stop community transmission.

27 Conclusion: The spread rate of COVID-19 is very high and until now no vaccines are available

28 to control this disease. To this end we should leverage other avenues such as digital technologies

29 to protect ourselves from this disease. Mobile technology such as smartphones are playing an

30 important role in this pandemic, by launching apps to track coronavirus infected people. These

31 apps are very easy to use and provide self-isolation guidelines as well as other safety tips.

\section{Introduction}

33 The coronavirus disease 19 (COVID-19) is a highly transmissible and pathogenic viral infection caused by severe acute respiratory syndrome coronavirus 2 (SARS-CoV-2), which emerged in

35 Wuhan, China and spread around the world (Matthew et al., 2020). Coronaviruses belong to the family of Coronaviridae in the Nidovirales order. Corona represents crown-like spikes on the outer

37 surface of the virus (https://3D_medical_animation_coronavirus_structure); thus, it was named as a coronavirus (Jie et al., 2018). Coronaviruses are minute in size (65-125 nm in diameter) and 
39 contain a single-stranded RNA as a nucleic material, size ranging from 26 to $32 \mathrm{kbs}$ in length (Fig.

40 1a). The subgroups of the coronaviruses family are alpha $(\alpha)$, beta $(\beta)$, gamma $(\gamma)$, and delta $(\delta)$

41 coronavirus. The severe acute respiratory syndrome coronaviruses (SARS-CoV), H5N1 influenza

42 A, H1N1 2009, and Middle East respiratory syndrome coronavirus (MERS-CoV) have been shown

43 to progress in some patients to acute lung injury (ALI) and acute respiratory distress syndrome

44 (ARDS) which leads to pulmonary failure and fatality (Zhong et al. 2003; Wang et al., 2013;

45 Shereen et al., 2020).

46 Coronavirus is easily transmitted through coughing and sneezing. Due to its high rate of spread it

47 is important to follow government guidelines to reduce (Fig 1b) (positivebioscience.com). In this

48 case, the best way to protect people; stay home, take precautions, and eat healthily to strengthen

49 our immune system till vaccine development, suggested by WHO

50 (www.who.int/blueprint/priority-diseases).

\subsection{COVID-19 detection}

52 According to the World Health Organization, diagnostic testing for COVID-19 is critical to

53 tracking the virus, understanding the epidemiology, informing case management, and suppressing

54 transmission. Amy et al., 2020 described the strategic use of diagnostic testing through many in-

55 house and commercial assays to detect the COVID-19 virus. Many of these molecular assay tests

56 are currently being validated. Samples for assay testing can be collected several different sites in 
57 the patient. Samples can be taken nasally or via the back of the throat (Amy et al., 2020). For

58 patients in the hospital, a sample from the lower respiratory tract may provide the best results.

59 Antigen testing reveals whether someone has a current infection and could therefore pass Covid-

6019 on to others (www.ft.com). In contrast, antibody (or serological) tests uses blood samples to

61 detect the immunity conferred by past infection. The kits used for antibody testing use proteins

62 from the virus as "glue" to trap antibodies present in the blood (Smriti et al., 2020)

\subsection{Epidemiological summary}

64 Almost 50 hundred thousand cases of coronavirus disease were reported from 31 December 2019

to 11 May 2020, including around 28 hundred thousand deaths shown in Fig. 2 based on a report conducted by European Centre for disease control and Prevention in 2020 (www.ecdc.europa.eu).

Table 1, provides a global representation of the COVID-19 pandemic (Jun et al., 2020). At present, COVID-19 (Coronavirus Disease-2019) is a public health emergency of international concern (Wu et al., 2020). While investigations are ongoing, at the time of publication, there is no known specific, effective, proven, pharmacological treatment (Angela et al., 2020, Priyanka et al., 2020). Invitro studies have suggested that chloroquine, an immunomodulant drug traditionally used to treat malaria, is effective in reducing viral replication in other infections, including the SARSassociated coronavirus (CoV) and MERS-CoV (Meo et al. 2020, Saleh et al. 2020). However, the

74 efficacy and safety of chloroquine for the treatment of SARS-CoV-2 pneumonia remains unclear. 
75 WHO and other research institutes are continuing on work on vaccine development

76 (www.who.int/blueprint/priority-diseases). Given the lengthy process of investigating therapies

77 for stopping COVID-19, mitigation strategies remain an important and effective facet in slowing

78 the virus spread. One such mitigation strategy is the use of mobile 81 technology (Colson et al.,

79 2020; Savarino et al., 2003, Emma et al., 2020).

80 According to a 2008 Bulletin of the World Health Organization, mobile technology played a

81 significant role during the China earthquake. The 2008 earthquake with a magnitude of 8.0 struck

82 the northwestern region of Sichuan province, China. More than 80,000 people were killed and 5

83 million more became homeless. An urgent issue associated with the aftermath the earthquake was

84 the efficient detection of occurrences of epidemic-prone diseases so that quick action could be

85 taken to prevent outbreaks. Before the earthquake, the local health-care agencies were required to

86 report 38 types of infectious diseases, as mandated by the law on prevention and treatment of

87 infectious diseases, through the Chinese information system for disease control and prevention

88 (CISDCP) to a national database (Ma et al. 2006). In Sichuan, an electronic dial up/landline

89 internet-based disease surveillance system has been in place in all townships since 2004. However,

90 the earthquake paralyzed much of the traditional landline-based infrastructure in many affected

91 areas. While working to repair the landline-based reporting system, the Chinese Center for Disease

92 Control and Prevention (China CDC) developed an emergency reporting system based on mobile

93 phones. Yang et al. 2009 explained the system and the lessons learned from the utilization of 
94 mobile phones for infectious disease surveillance after the catastrophic earthquake. The current

95 surveillance system leveraging mobile phone technology has played an important role during

96 COVID-19 (Emma et al., 2020).

97 In this pandemic, digital technologies like smartphone applications (apps) using Bluetooth

98 technology are needed to track infected people in nearby areas (en.unesco.org). Such apps are

99 developed worldwide by the U.S.A., Singapore, India, U.K., and many other countries to track and

100 control the coronavirus disease (Boutheina et al., 2020). These apps provide self-quarantine and

101 other safety information to users. The authors argue that if greater numbers of people downloaded

102 and used these sorts' apps, there is potential to decrease the spread rate of the coronavirus disease.

103 A detailed study of these smartphone apps are discussed in this article within the context of the

104 COVID-19 response.

105 2. Literature Review Methodology

106 This review article has been structured after collecting data from COVID-19 published articles

107 from sources including but not limited to from nature.com, Elsevier, science direct.com, Royal

108 Society of Chemistry publishing articles, and American Chemical Society articles. Shereen et al.,

1092020 discussed COVID-19 infection, its origin, transmission, and characteristics. Some of major

110 supportive literatures for this article are; Colson et al., 2020 addressed treatment and vaccine

111 progress for coronavirus. Jessica et al. 2020 described ethical guidelines for contact tracing apps. 
112 Rocher et al. 2020 presented evidence that 'apps for COVID-19 contact-tracing are secure and

113 effective'. These articles have played an important role in the literature review for this article. In

114 addition, the authors used Google to identify the top 10 mobile apps used track COVID-19 which

115 revealed www.geospatialworld.net, https://healthtech.blog.gov.uk, and

116 www.bbc.com/news/technology.

\section{3. Smartphone Technology to fight against COVID-19}

118 Smartphone apps are playing an important role in the response to the Covid-19 pandemic (Yang

119 et al. 2009). These apps are being used to track infected people, issue self-quarantine guidelines,

120 provide the latest communication to the citizens and ease the burden on healthcare staff throughout

121 the world (Ma et al. 2006). The apps have been downloaded by millions of people. Technology is

122 providing an important role in the diagnosis of those affected, identifying hotspots, and providing

123 real-time information updates (Villa et al. 2020). This article, provides discussion of popular

124 smartphone apps specific to tracking the Covid-19 outbreak (www.geospatialworld.net/popular-

125 apps-covid-19).

\section{$126 \quad 3.1$ TraceTogether}

127 TraceTogether is a popular smartphone contact tracking app that uses Bluetooth to track infected

128 people and alert people who have been close to them in the past 15 days. Anyone with a Singapore 
129 mobile number and a Bluetooth enabled smartphone can download this app

130 (www.mobihealthnews.com).

131 The application was developed by the Government Technology Agency (GovTech) in

132 collaboration with the Ministry of Health $(\mathrm{MOH})$ and has become a prototype for many other

133 contact tracking applications in other parts of the world. When two people using the app are close,

134 both phones will use Bluetooth to exchange a temporary ID. This temporary identification is

135 generated by encrypting the identification of the user with a private key held by the MOH. The

$136 \mathrm{MOH}$ can only decipher it and does not reveal its identity or the identity of the other person. This

137 application does not collect data on the position of the GPS or the Wi-Fi / mobile network.

\section{$138 \quad 3.2$ Aarogya Setu}

139 In this app, monitoring is done via Bluetooth and a location-generated graph that records proximity

140 to any infected person. This app has been developed by the Indian Ministry of Electronics and it

141 notifies users if they have crossed paths with someone who has been diagnosed positive for Covid-

14219 (www.businesstoday.in). India is also using various other apps such as 'Kerala solutions',

143 'Tracking quarantine', 'More than just tracking' to track and trace Covid-19. These apps are cross-

144 communicate to each other and would be helpful for entire country people, who are using these

145 apps.

$146 \quad 3.3$ COVID Symptom Tracker 
147 Scientists analyzed the high-risk areas in the United Kingdom, the rate of spread of the virus, and

148 the most vulnerable groups, depending on health conditions to develop this app. 'Covid Symptom

149 Tracker was designed by doctors and researchers from King's College London and St. Thomas

150 hospitals, in association with a private health company called Zoe Global (www.bbc.com). This

151 app monitors virus symptoms for ongoing research and also tracks virus among those using the

152 app. The app complies with the general data protection regulation (GDPR) and the data is used

153 only for health research and not for commercial purposes.

154 3.4 The Corona DataSpende

155 This is a German smart-watch app and monitors the spread of coronavirus by collecting vital signs

156 (heart rate, sleep patterns, body temperature) from volunteers using a smart-watch or physical

157 activity tracker (in.reuters.com). This app can check whether a person has developed symptoms of

158 Covid-19 or not. The results are displayed on an interactive online map that allows health

159 authorities to take stock of the situation and determine hotspots.

\section{$160 \quad 3.5$ CovidWatch}

161 This application allows people to protect themselves and their communities while ensuring

162 privacy. This app is designed in collaboration with Stanford University (https://covid-watch.org).

163 It uses Bluetooth signals to detect users when they are nearby and warns them anonymously if they 
164 were in contact with someone who had tested positive. It was one of the first applications to launch

165 an open-source protocol for decentralized tracking of Bluetooth contacts that preserves privacy. A

166 distinctive feature of the app is that any third party, including the government, will not be able to

167 track who has been exposed by whom.

\section{$168 \quad 3.7$ NHS smartphone app}

169 This contact tracking application, developed by the British National Health Service. The app was

170 designed by NHSX (the NHS innovation unit) and will be released in the near future

171 (healthtech.blog.gov.uk). The app will maintain control of people's movements and alert those who

172 come into contact with those who have been infected. The NHS suggests that by analyzing virus

173 spread patterns and hotspots, the app would also help in relaxing lockdown. The app would classify

174 user details based on demographics, home structures and mobility patterns. Based on the data

175 analysis a maximum number of people could be established and allowed to move freely. British

176 health secretary Matt Hannock urged the public to download the app as soon as it becomes 177 available.

\section{$178 \quad 3.6$ Let's Beat Covid-19}

179 This app was developed by MedShr, used by more than one million physicians in diagnosis of 180 Covid-19 (https://techcrunch.com). LetsBeatCOVID.net is designed to allow members of the 
181 public to complete a short survey on their health and exposure to COVID-19 so that health services

182 can identify at risk individuals. The public is invited to complete a brief anonymous survey of

183 them and is also allowed to enter information about their family members.

\section{$184 \quad 3.8$ HaMagen}

185 This application was launched by the Israeli Ministry of Health and uses contact monitoring to

186 contain the spread of deadly infection (https://omny.fm/shows/english-news-highlights/health

187 ministry-launches-app-to-help-prevent-corona). The application lets users to know if they have

188 been close to someone diagnosed with the virus in the past fifteen days. Once a user installs the

189 application their movements are tracked using location technology, and the information obtained

190 is compared with the ministry's data on that particular location for diagnosed people. If a particular

191 user was very close to an infected person, the app redirects the person to the Ministry of Health

192 website where they can register for quarantine.

\section{3.9 Kwarantana Dommowa}

194 Poland was one of the first western countries to launch a smartphone app that collects a great deal

195 of personal information, including the location of people and digital photos

196 (https://apk.center/pl.nask.droid.kwarantannadomowa). When using this app, people upload their

197 selfie image when requested by app administrative agents, so they can determine their exact

198 location. This app is mandatory for anyone who has developed coronavirus symptoms in Poland. 
199

200

201

202

203

204

205

206

207

208

209

210

211

212

213

214

215

\subsection{PeduliLindungi}

This application has been developed by the Indonesian Ministry of Communications and information, together with the Ministry of State Societies (SOE). This application allows users to collect data related to the spread of COVID-19 in their communities and help strengthen government efforts to track confirmed cases as well as those suspected of being infected with the virus (https://www.suara.com). When a user is close to another user whose data has been uploaded to PeduliLindungi, the app allows anonymous identity exchange, according to its official website.

\subsection{Limitations of smartphone technology}

A major limitation is that any contact tracing plan must reach a critical mass in order to be effective.

People need to both download an app and update their real health status through any given downloaded app (www.healthcareitnews.com). Success in terms of health status data collections depends on messaging and how it is presented to the user. Messaging should emphasize that apps provide disease mitigation and protection for individual users and others at large (https://thewire.in/tech/covid-19).

Mobile app technology related to Covid-19 or other epidemic and pandemic diseases requires data aggregation from multiple smartphones to compute intersections of trajectories. Such aggregation will be hard to implement at scale if such app use remains decentralized and centralization will 
216 require additional infrastructure. Even with centralized aggregation, rigorously estimating the

217 dynamic network parameters and the associated error models will be a non-trivial task, especially

218 without near-universal participation (www.hausfeld.com). At best, mobility data may be used for

219 modeling macro-level patterns of infection spread that too with several simplifying assumptions

220 with uncertain error models (www.un.org). Besides, making such apps universal, and centralized

221 aggregation with support from mobile service providers, Google, and indoor Wi-Fi providers, will

222 certainly be beyond individual app developers and will require governmental support

223 (www.cbsnews.com). China leveraged facial recognition technology, with existing infrastructure

224 that was already in place. While this tactic has been successful in China, there are serious privacy

225 and data protection concerns that need to be addressed - in terms of legitimacy and proportionality,

226 regulatory oversight, access control, and purpose limitation (Jessica et al. 2020).

227 Each presented and future app-based technology specific to Covid-19 and other epidemic and

228 pandemic diseases presents with both advantages and limitations. These advantages and

229 limitations must be rigorously evaluated and taken into account when choosing the best app to

230 meet disease process and population needs (www.fireeye.com).

231 4. Discussion

232 Researchers around the world are rushing to create vaccines and medicines that can stop the

233 COVID-19 pandemic or at least halt its spread. In the midst of these efforts, there is evidence that 
234 technology can play a useful role in mitigating the crisis and facilitate a valuable contribution to

235 this global battle (Daniel et al. 2020). The use of mobile devices as part of this effort has raised

236 several important questions around privacy and security (www.weforum.org). COVID-19 tracking

237 apps fall into three main categories: 1) understanding general population movement, 2) potential

238 proximity to COVID-19 positive individuals and advice on measures for self-quarantine, and 3)

239 the collection of information from patients for statistical analysis (www.uclg.org)

4.1 Mobile tracking to understand population movement and the impact of lockdown

241 Mobile carriers in Germany, Italy, and France have started to share mobile location data with

242 health officials in the form of aggregated, anonymized information and is consistent with local law

243 and regulations. Because European Union member countries have very specific rules about how

244 any app and device users must consent to the use of personal data, developers must consider other

245 forms of useful data unless they solicit and receive individual consent from users. The aggregated

246 and anonymized approach is related to groups within a population and not individuals, but it can

247 provide a clear view of population displacement trends and therefore disease transmission risk

248 level of geographic areas (www.fireeye.com).

This approach is being explored in countries such as Germany and France. The objective is to limit

251 the spread of the virus by identifying people who have potentially come into contact with an

252 individual who has tested positive, and by advising those people to self-quarantine, if proximity 
253 was determined. In Germany, the government is relying on the rules defined by the Pan-European

254 Privacy-Preserving Proximity Tracing (PEPP-PT). France is exploring this subject with INRIA

255 (The National Institute for Research in Computer Science and Automation) under the project:

256 ROBERT (ROBust and privacy-preserving proximity tracing) 260 protocol (Rachel et al., 2020).

\subsection{Collection of users' information for statistical analysis}

258 This approach has been used by the UK government through the application 'C-19 COVID

259 Symptom Tracker', which was developed by the startup ZOE in association with King's College

260 London. The data needed to meet all three objectives are then stored by mobile providers in a

261 variety of places that must be secured, both to protect the app users' privacy but also to prevent

262 manipulation/spoiling of the data by a third party. In this case data is sourced from different places,

263 like repositories of GPS, Bluetooth, and other apps on the device, different security arrangements

264 by the source may need to be considered (Jessica et al. 2020).

265 Regulators are recognizing that app developers need timely guidance to balance the collection of data with safeguarding privacy. In the EU, the statement by the EDPB Chair on the processing of

267 personal data in the context of the COVID-19 outbreak, published in March 2020, advances this objective (www.uclg.org). In this field of research, app providers must to ensure an appropriate level of security, to avoid any data leaks and any data manipulation by non-trusted third parties. 


\section{5. Conclusion}

273 The coronavirus is believed to have started to spread from the Hunan seafood market at Wuhan,

274 China and quickly spread up to 215 countries. While various clinical trails have begun as it relates

275 to vaccine availability and treatment therapies, at present, there remain no approved evidence-

276 based vaccines or therapies for the treatment human coronaviruses, specifically Covid 19.

277 Scientists and researchers are continuously working to develop efficient therapeutic strategies to cope with the COVID-19. There are numerous organizations working towards the advancement of successful SARS-CoV-2 vaccines, but these vaccines still require months for commercialization after rapid human and animal-based successful trails. In the meantime, control of virus spread remains paramount. Mobile technology, app-based technology is playing an important in various countries by tracking virus spread and providing information related to best-practices in mitigations such as self-quarantine. These apps are easy use and successful broad adoption will likely increase as the literature begins and continues to report the effectiveness of this technology (https://thewire.in/tech/covid-19). As the saying goes, 'a crisis provides an opportunity'; this first great crisis of 2020 provides an opportunity to establish best practices in the use of mobile technology for healthcare purposes. The potential benefits of digital app-based healthcare interventions seem particularly compelling for managing chronic conditions such as diabetes and hypertension (https://hbr.org/2018) 
290 Acknowledgments: We would like to thank Eric B. Bauman, Lisa Buckley and Arun Mathews

291 for their comments, insightful suggestions, and careful reading of the manuscript.

292 References:

293

294

295

296

297

298

299

300

301

302

303

304

305

306

307
1. Amy M. The researchers taking a gamble with antibody tests for coronavirus. 2020. News. Nature.

2. Angela BG, Moran F, Rafal K. 2020. The race against COVID-19. Editorial. Nature Nanotechnology. 4:1-2.

3. Boutheina G. 2020. Leveraging digital technology to tackle COVID-19: The power of joint action, world bank blog, Digital Development. Available at blogs.worldbank.org

4. Colson P, Rolain JM, Raoult D. 2020. Chloroquine for the 2019 novel coronavirus SARSCoV-2. Int J Antimicrob Age. 55:1-2.

5. Coronavirus tracking app 2020. Available at https://www.bbc.com/news/technology52033210.

6. COVID Watch, 2020. Available at https://covid-watch.org/

7. COVID-19 - Contact Tracing Apps: Privacy and Interoperability Concerns Remain. 2020. Available at www.hausfeld.com

8. Daniel SWT, Lawrence C, Victor D, Tien YW. 2020. Digital technology and COVID-19. Nature Medicine. 26:459-461. 
308

309

310

311

312

313

314

315

316

317

318

319

320

321

322

323

324

325
9. Department of Economic and Social Affairs- Digital technologies critical in facing COVID-19 pandemic. 2020. Available at www.un.org.

10. Emma S. 2020. Daily briefing: Hundreds volunteer for controversial coronavirus vaccine study. News. Nature.

11. European Centre for disease control and Prevention, 2020. Available at https://www.ecdc.europa.eu/en/antimicrobial-consumption/surveillance-and-diseasedata/database.

12. Fighting COVID-19 through digital innovation and transformation. 2020. Available at en.unesco.org/covid19/communicationinformationresponse/digitalinnovation

13. Germany launches smartwatch app to monitor coronavirus spread. 2020. Available at in.reuters.com

14. India's Digital Response to COVID-19 Risks Creating a Crisis of Trust. 2020. Available at https://thewire.in/tech/covid-19.

15. Home Quarantine (Kwarantanna domowa), 2020. Available at https://apk.center/pl.nask.droid.kwarantannadomowa.html 16. Indonesian mobile app for COVID-19, 2020. Available at https://www.suara.com/tekno/2020/04/16/130005/melihat-cara-kerja-aplikasipedulilindungi. 
326

327

328

329

330

331

332

333

334

335

336

337

338

339

340

341

342

343

344
17. Israel's smartphone app for COVD-19, 2020. Available at https://omny.fm/shows/englishnews-highlights/health-ministry-launches-app-to-help-prevent-coron

18. Jessica M, Josh C, Mariarosaria T. Luciano F. 2020. Ethical guidelines for contact tracing apps. Nature. 582:29-31.

19. Jie C, Fang L, Zheng LS. 2018. Origin and evolution of pathogenic coronaviruses. Nature Reviews Microbiology. 17:181-192

20. Jun C, Hongzhou L, Gerry M, Stefania B, Mauro P, Walter R, Ying W, Yufang S, Tongyu Z. 2020. COVID-19 infection: the China and Italy perspectives. Cell death and Disease. 11:1-17.

21. LetsBeatCOVID.net, 2020. Available at https://techcrunch.com/2020/03/24/letsbeatcovidnet-launches-to-track-the-spread-of-the-coronavirus-in-the-uk

22. Live Learning Experience: Beyond the immediate response to the outbreak of COVID-19: Digital Technologies and the COVID19 pandemic. 2020. Available at www.uclg.org.

23. Luc R. Julien M, Hendrickx, YA. 2019. Estimating the success of re-identifications in incomplete datasets using generative models. Nature Comm. 10: 1-9.

24. Ma JQ, Yang GH, Shi XM. 2006. Disease surveillance based information technology platform in China Ji Bing Jian Ce. 21: 1-3.

25. Matthew ZT, Chek MP, Laurent R, Paul AM, Lisa FPN. 2020. The trinity of COVID-19: immunity, inflammation and intervention. Nature Reviews Immunology. 20: 363-374. 
345

346

347

348
26. Meo SA, Klonoff DCA. 2020. Efficacy of chloroquine and hydroxychloroquine in the treatment of COVID-19. J.Eur Rev Med Pharmacol Sci. 24:4539-4547.

27. Mobile heath news, Singapore, 2020. Available at https://www.mobihealthnews.com/news/asia-pacific/singapore-government-launchesnew-app-contact-tracing-combat-spread-covid-19.

28. Positive Biosciences 2020. Available at https://positivebioscience.com

29. Privacy, security concerns as India forces virus-tracing app on millions. 2020. Available at www.cbsnews.com.

30. Priyanka P. 2020. India expands use of controversial drug for coronavirus despite safety concerns. News. Nature

31. Rachel AM, Fahmi H, Kakamad AM, Salih, SH, Mohammed LD, Andreas O. 2020. Share mobile data to curb COVID-19. Nature. 580: 29.

32. Saleh M, Gabriels J, Chang D, Kim BS, Mansoor A, Mahmood E, Makker P, Ismail H, Goldner B, Willner J, Beldner S, Mitra R, John R, Chinitz J, Skipitaris N, Mountantonakis S, Epstein LM. 2020. The Effect of Chloroquine, Hydroxychloroquine and Azithromycin on the Corrected QT Interval in Patients with SARS-CoV-2 Infection. Circ: Arrhythm Electrophysiol. 2:1-34 
363

364

365

366

367

368

369

370

371

372

373

374

375

376

377

378

379

380

381
33. Savarino A, Boelaert JR, Cassone A, Majori G, Auda R. 2003. Effects of chloroquine on viral infections: an old drug against today's diseases. Lancet Infect Dis. 3:722-7.

34. Shereen MA, Khan S, Kazmi A, Bashir N, Siddique R. 2020. COVID-19 infection: Origin, transmission, and characteristics of human coronaviruses. Journal of Advanced Res. 24:91-98.

35. Show evidence that apps for COVID-19 contact-tracing are secure and effective. 2020. Nature, 580:563.

36. Smartphone apps to track COVID-19, 2020. Available at https:/www.geospatialworld.net/blogs/popular-apps-covid-19/

37. Smriti M. 2020. Antibody tests suggest that coronavirus infections vastly exceed official counts. News. Nature.

38. Technology can help diagnose, contain COVID-19 - within limits.2020. Available at https://www.healthcareitnews.com

39. Technology in the NHS. 2020. Available at https://healthtech.blog.gov.uk/2019/05/31/thenhs-app-a-platform-for-innovation.

40. The Security and Privacy Implications of COVID-19 Location Data Apps. 2020. Available at www.fireeye.com

41. Villa A, Sankar V, Shiboski C. 2020. Tele (oral) medicine: A new approach during the COVID-19 crisis. Oral Diseases. 5: 1-2. 
382

383

384

385

386

387

388

389

390

391

392

393

394

395

396

397

398

399
42. Wang N, Shi X, Jiang L, Zhang S, Wang D, Tong P. 2013. Structure of MERS-CoV spike receptor-binding domain complexed with human receptor DPP4. Cell Res. 23:986

43. What coronavirus tests does the world need to track the pandemic. 2020. Available at https://www.ft.com/content/0faf8e7a-d966-44a5-b4ee-8213841da688

44. WHO-Information about COVID-19. 2020. Available at

https://www.businesstoday.in/technology/news/coronavirus

45. Why-apps-for-managing-chronic-disease. 2018. available at https://hbr.org/2018

46. World Economic Forum- 10 technology trends to watch in the COVID-19 pandemic. 2020.

Available at www.weforum.org

47. World Health Organization report, 2020. Available at

https://www.who.int/blueprint/priority-diseases/keyaction/Table_of_therapeutics_

Appendix_17022020.pdf?ua=1.

48. Wu Z, McGoogan JM. 2020. Characteristics of and important lessons from the coronavirus disease 2019 (COVID-19) outbreak in China: summary of a report of 72314 cases from the Chinese Center for Disease Control and Prevention. JAMA. 13:1239-1242.

49. Yang C, Yang J, Luo X, Gong P. 2009. Use of mobile phones in an emergency reporting system for infectious disease surveillance after the Sichuan earthquake in China, Bulletin of the World Health Organization. 87:619-623. 
400

401

402

403

404
50. Zhong N, Zheng B, Li Y, Poon L, Xie Z, Chan K. 2003. Epidemiology and cause of severe acute respiratory syndrome (SARS) in Guangdong, People's Republic of China, in February. The Lancet. 362:1353-1358.

51. 3D medical animation still shot showing the structure of a coronavirus, 2020. Available at https://commons.wikimedia.org/wiki/File:3D_medical_animation_coronavirus_structure 
Figure 1

(A) Structure of corona virus (B) The symptoms of covid-19 \& how it spreads.

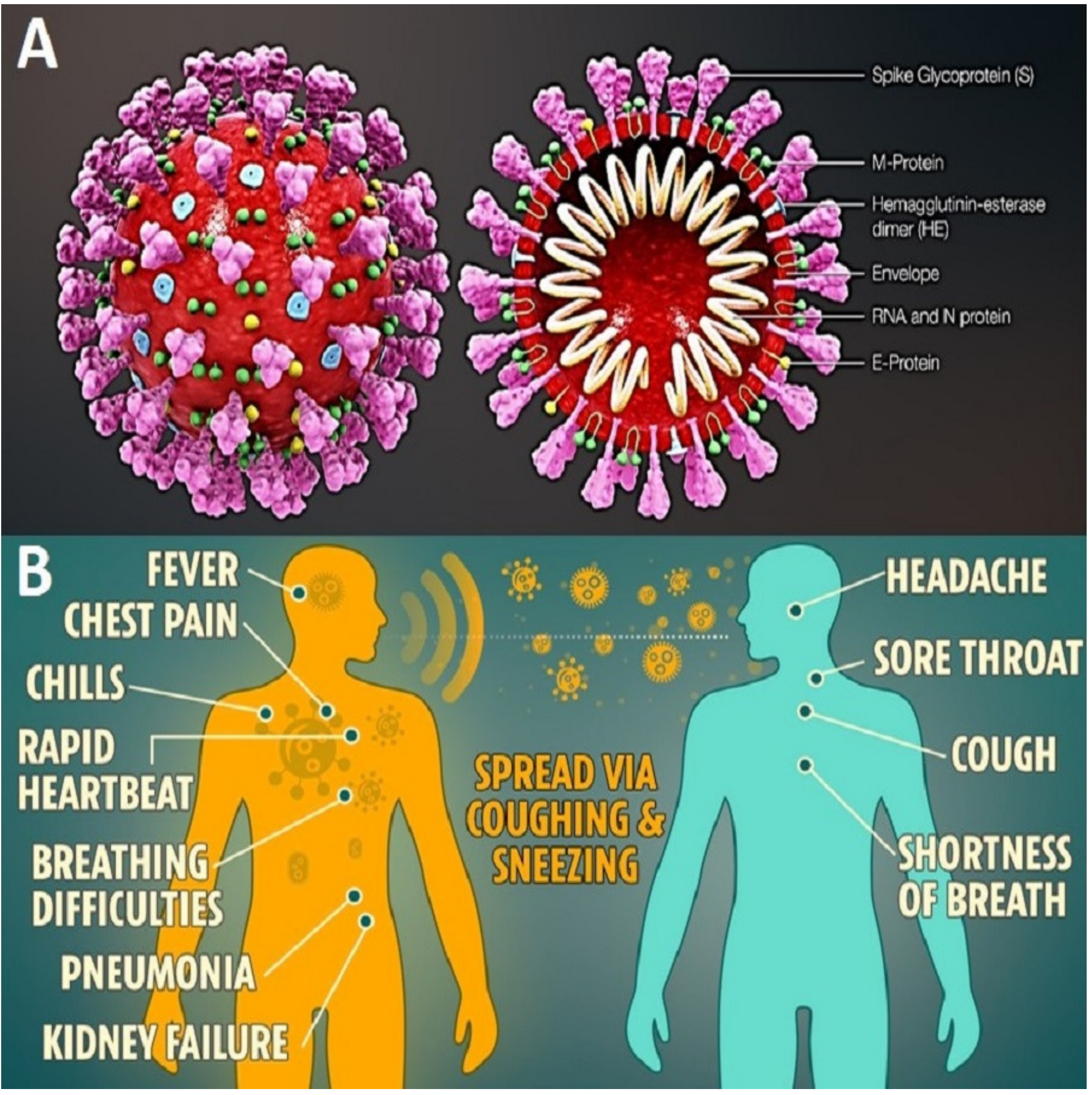


Figure 2

(A) Day-to-day distribution of confirmed cases (B) Distribution of daily death of (C) Distribution of cumulative death (D) Comparison between Actual Death and death rate (E) Death Rate distribution, of COVID-19 of top 40 countries, over the continent. 

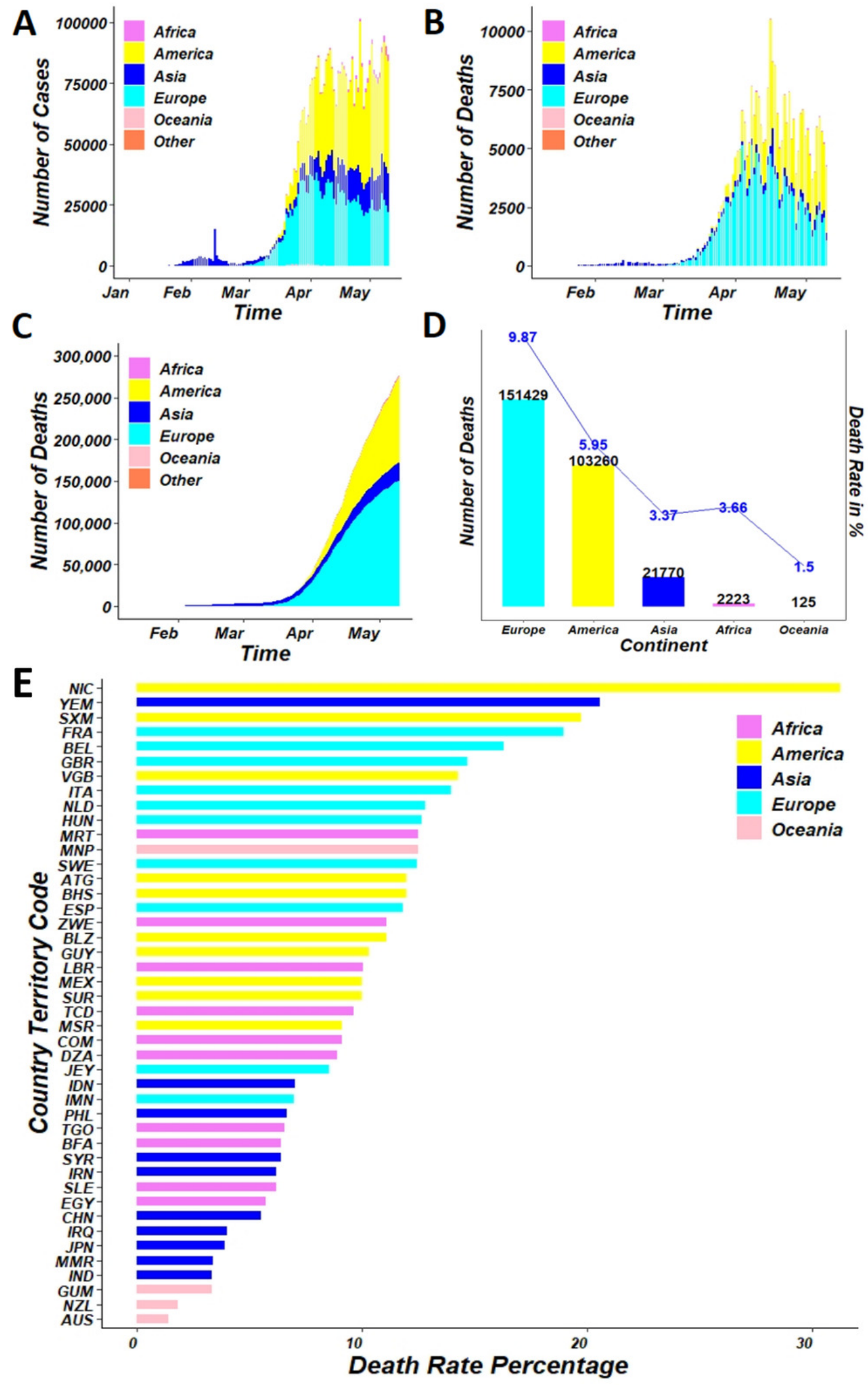


\section{Table 1 (on next page)}

Global scenario over active and death cases of COVID-19. 
1

\begin{tabular}{|c|c|c|c|c|c|c|c|}
\hline \multirow{2}{*}{$\begin{array}{l}\text { Rank of } \\
\text { Continent }\end{array}$} & \multirow{2}{*}{ Continent } & \multicolumn{3}{|c|}{ Cases } & \multicolumn{3}{|c|}{ Deaths } \\
\hline & & Rank & Country & Status & Rank & Country & Status \\
\hline \multirow[t]{5}{*}{1} & \multirow{5}{*}{$\begin{array}{c}\text { America } \\
\text { (Total Cases - } 1736710 \\
\text { Total Deaths - } 103260\end{array}$} & 1 & $\begin{array}{c}\text { United States of } \\
\text { America }\end{array}$ & 78794 & 1 & $\begin{array}{c}\text { United States of } \\
\text { America }\end{array}$ & 78794 \\
\hline & & 2 & Brazil & 10627 & 2 & Brazil & 10627 \\
\hline & & 3 & Canada & 4693 & 3 & Canada & 4693 \\
\hline & & 4 & Peru & 1814 & 4 & Mexico & 3353 \\
\hline & & 5 & Mexico & 3353 & 5 & Peru & 1814 \\
\hline \multirow[t]{5}{*}{2} & \multirow{5}{*}{$\begin{array}{c}\text { Europe } \\
\text { (Total Cases - } 1534605 \\
\text { Total Deaths - } 151429\end{array}$} & 1 & Spain & 26478 & 1 & United Kingdom & 31587 \\
\hline & & 2 & Italy & 30395 & 2 & Italy & 30395 \\
\hline & & 3 & United Kingdom & 31587 & 3 & Spain & 26478 \\
\hline & & 4 & Russia & 1827 & 4 & France & 26310 \\
\hline & & 5 & Germany & 7395 & 5 & Belgium & 8581 \\
\hline \multirow[t]{5}{*}{3} & \multirow{5}{*}{$\begin{array}{c}\text { Asia } \\
\text { (Total Cases - } 645103 \\
\text { Total Deaths - } 21770\end{array}$} & 1 & Turkey & 3739 & 1 & Iran & 6589 \\
\hline & & 2 & Iran & 6589 & 2 & China & 4637 \\
\hline & & 3 & China & 4637 & 3 & Turkey & 3739 \\
\hline & & 4 & India & 2109 & 4 & India & 2109 \\
\hline & & 5 & Saudi Arabia & 239 & 5 & Indonesia & 959 \\
\hline \multirow[t]{5}{*}{4} & \multirow{5}{*}{$\begin{array}{c}\text { Africa } \\
\text { (Total Cases - } 60661 \\
\text { Total Deaths - } 2223\end{array}$} & 1 & South Africa & 186 & 1 & Egypt & 514 \\
\hline & & 2 & Egypt & 514 & 2 & Algeria & 494 \\
\hline & & 3 & Morocco & 186 & 3 & Morocco & 186 \\
\hline & & 4 & Algeria & 494 & 4 & South Africa & 186 \\
\hline & & 5 & Ghana & 22 & 5 & Nigeria & 128 \\
\hline \multirow[t]{4}{*}{5} & \multirow{4}{*}{$\begin{array}{c}\text { Oceania } \\
\text { (Total Cases - } 8344 \\
\text { Total Deaths - } 125\end{array}$} & 1 & Australia & 97 & 1 & Australia & 97 \\
\hline & & 2 & New Zealand & 21 & 2 & New Zealand & 21 \\
\hline & & 3 & Guam & 5 & 3 & Guam & 5 \\
\hline & & 4 & $\begin{array}{c}\text { Northern Mariana } \\
\text { Islands }\end{array}$ & 2 & 4 & $\begin{array}{c}\text { Northern Mariana } \\
\text { Islands }\end{array}$ & 2 \\
\hline 6 & $\begin{array}{c}\text { Others } \\
\text { (Total Cases - } 696 \\
\text { Total Deaths - } 7\end{array}$ & 1 & $\begin{array}{c}\text { Cases on an } \\
\text { international } \\
\text { conveyance Japan }\end{array}$ & 696 & 1 & $\begin{array}{c}\text { Cases on an } \\
\text { international } \\
\text { conveyance Japan }\end{array}$ & 7 \\
\hline
\end{tabular}

